\title{
The association of acute hypercarbia and plasma potassium concentration during laparoscopic surgery: a retrospective observational study
}

Laurence Weinberg ${ }^{1,2^{*}} \mathbb{D}$, Dong-Kyu Lee ${ }^{3}$, Chrisdan Gan ${ }^{1}$, Damian lanno ${ }^{1}$, Alexander Ho ${ }^{1}$, Luke Fletcher ${ }^{1}$, Daniel Banyasz ${ }^{1}$, Shervin Tosif ${ }^{1}$, Daryl Jones ${ }^{4,5}$, Rinaldo Bellomo ${ }^{4}$ and Dharshi Karalapillai ${ }^{1,4}$

\begin{abstract}
Background: It is uncertain whether increases in $\mathrm{PaCO}_{2}$ during surgery lead to an increase in plasma potassium concentration and, if so, by how much. Hyperkalaemia may result in cardiac arrhythmias, muscle weakness or paralysis. The key objectives were to determine whether increases in $\mathrm{PaCO}_{2}$ during laparoscopic surgery induce increases in plasma potassium concentrations and, if so, to determine the magnitude of such changes.

Methods: A retrospective observational study of adult patients undergoing laparoscopic abdominal surgery was perfomed. The independent association between increases in $\mathrm{PaCO}_{2}$ and changes in plasma potassium concentration was assessed by performing arterial blood gases within 15 min of induction of anaesthesia and within 15 min of completion of surgery.

Results: 289 patients were studied (mean age of 63.2 years; 176 [60.9\%] male, and mean body mass index of $29.3 \mathrm{~kg} /$ $\left.\mathrm{m}^{2}\right)$. At the completion of the surgery, $\mathrm{PaCO}_{2}$ had increased by $5.18 \mathrm{mmHg}(95 \% \mathrm{Cl} 4.27 \mathrm{mmHg}$ to $6.09 \mathrm{mmHg})$ compared to baseline values $(P<0.001)$ with an associated increase in potassium concentration of $0.25 \mathrm{mmol} / \mathrm{L}(95 \%$ $\mathrm{Cl} 0.20 \mathrm{mmol} / \mathrm{L}$ to $0.31 \mathrm{mmol} / \mathrm{L}, \mathrm{P}<0.001)$. On multiple regression analysis, $\mathrm{PaCO}_{2}$ changes significantly predicted immediate changes in plasma potassium concentration and could account for $33.1 \%$ of the variance $\left(r^{2}=0.331\right.$, $f(3,259)=38.915, P<0.001)$. For each $10 \mathrm{mmHg}$ increment of $\mathrm{PaCO}_{2}$ the plasma potassium concentration increased by $0.18 \mathrm{mmol} / \mathrm{L}$.
\end{abstract}

Conclusion: In patients receiving laparoscopic abdominal surgery, there is an increase in $\mathrm{PaCO}_{2}$ at the end of surgery, which is independently associated with an increase in plasma potassium concentration. However, this effect is small and is mostly influenced by intravenous fluid therapy (Plasma-Lyte 148 solution) and the presence of diabetes.

Trial registration Retrospectively registered in the Australian New Zealand Clinical Trials Registry (Trial Number: ACTRN12619000716167).

Keywords: Anaesthesia, Potassium, Hypercarbia, Laparoscopic, Surgery

${ }^{*}$ Correspondence: laurence.weinberg@austin.org.au

1 Department of Anaesthesia, Austin Health, 145 Studley Road, Heidelberg 3084, Australia

Full list of author information is available at the end of the article

\section{Background}

Increased partial pressure of arterial carbon dioxide $\left(\mathrm{PaCO}_{2}\right)$ (hypercarbia) is common in the setting of mechanical ventilation and surgery $[1,2]$. The effect of hypercarbia and respiratory acidosis on plasma 
potassium concentrations $\left(\left[\mathrm{K}^{+}\right]_{\mathrm{p}}\right)$ is unclear with some studies showing an increase in concentration and others showing no effect [3-10]. Further, a body of longstanding evidence indicates that the hyperkalaemia-acidaemia relationship is more complex than the relatively simplistic, but commonly accepted notion that hyperkalaemia develops due to an increase in extracellular acidity and subsequent exchange of extracellular hydrogen ions for intracellular potassium ions [8]. Challenging this theory, early studies have shown that the directional flux of potassium during acute acid-base disorders is not uniform among various tissues [11-13]. During acute respiratory acidosis, potassium was shown to move extracellularly in skeletal muscle $[12,14,15]$ and liver tissue $[16,17]$, but intracellularly in cardiac tissue $[11,15$, 18, 19]. Whilst mild hyperkalaemia intraoperatively is usually asymptomatic, high plasma levels of potassium may result in cardiac arrhythmias, muscle weakness or paralysis. Understanding this relationship has specific implications for the prevention of severe hyperkalaemia and the immediate monitoring and management of hyperkalaemia in the intra- and postoperative periods, as timely recognition and treatment of complications that arise from hyperkalaemia is imperative.

These conflicting findings, together with a lack of information from large scale studies concerning the quantitative and temporal relationships between changes in $\mathrm{PaCO}_{2}$ and $\left[\mathrm{K}^{+}\right]_{\mathrm{p}}$ have clinical relevance during anaesthesia. Accordingly, a retrospective study was performed to describe the association between changes in $\mathrm{PaCO}_{2}$ and acute changes in $\left[\mathrm{K}^{+}\right]_{\mathrm{p}}$ in patients undergoing laparoscopic surgery. Laprascopic surgery is a well-described model of carbon dioxide absorption and subsequent hypercarbia during anaesthesia $[1,2,20-22]$. The following hypotheses were made. First, in alignment with the current literature [1,2], patients undergoing laparoscopic surgery would develop acute respiratory acidosis. Second, the development of any respiratory acidosis would cause acute respiratory acidaemia. Finally, there would be an acute rise in $\left[\mathrm{K}^{+}\right]_{\mathrm{p}}$ in response to the respiratory acidaemia. To test these hypotheses, patients undergoing extraperitoneal and intraperitoneal laparoscopic surgery were restrospectively studied in a university hospital.

\section{Methods}

The Austin Health Human Research Ethics Committee approved this study (LNR/19/Austin/41) and provided a waiver for participant consent. Between February 2015 and February 2019, data was collected from the medical records of all patients undergoing extraperitoneal and intraperitoneal laparoscopic abdominal surgery at university hospital. Patients were included if they underwent surgery of greater than two hours duration, received an arterial line as part of anaesthesia care and were hospitalised for at least one postoperative night. To accurately compare changes in $\mathrm{PaCO}_{2}$ and $\left[\mathrm{K}^{+}\right]_{\mathrm{p}}$ during surgery to baseline values, data was collected from patients who had an arterial blood gas sampled within 15 min of induction of anaesthesia and a subsequent arterial blood gas sampled within $15 \mathrm{~min}$ of completion of surgery. The study was registered the study with the Australian New Zealand Clinical Trials Registry (Trial number ACTRN12619000716167; registered 13th May 2019; available at http://www.anzct r.org.au/Trial/Registration/TrialReview.aspx?id $=37730$ $3 \&$ showOriginal $=$ true\&isReview $=$ true).

Conduct of anaesthesia, was at the discretion of the treating anaesthetist and in accordance with existing protocols for patients undergoing major laparoscopic surgery at our institution. All patients received balanced crystalloid fluid therapy with the buffered fluid Plasma-Lyte 148 solution (Baxter Healthcare, Toongabbie, Australia). The physiochemical and electrolyte composition of Plasma-Lyte 148 is similar to human plasma, with a $\mathrm{pH}$ of 7.4 and a potassium concentration of $5 \mathrm{mmol} / \mathrm{L}$.

During surgery, the handling and transportation of blood gas aspirates were performed using a standard hospital sampling protocol. A 3-5 mL sample of arterial blood was slowly aspirated into a $5 \mathrm{~mL}$ discard syringe minimising any force or strain during the aspiration process. Then, $1.0 \mathrm{~mL}$ of arterial blood was aspirated from the arterial line over a $2 \mathrm{~s}$ period and placed into a safePICO ${ }^{\mathrm{TM}}$ blood gas aspirator (Radiometer Medical Aps, Brenshel, Denmark) containing 80 IU electrolyte balanced heparin. This blood sampling technique is designed to minimise any in-vitro haemolysis, which can falsely increase values of plasma constituents, especially potassium. The safePICO aspirator has a clear $1.0 \mathrm{~mL}$ label designed for accurate blood sampling, which is necessary to produce reliable results.

The blood sample syringe was transported horizontally and at standard operating room temperature $\left(22{ }^{\circ} \mathrm{C}\right)$ to an automated blood gas analyser (ABL800, Radiometer, Denmark). $\left[\mathrm{K}^{+}\right]_{\mathrm{p}}, \mathrm{PaCO}_{2}$, and $\mathrm{pH}$ were measured directly by the analyser and automatically entered into the patient's electronic medical record. The same blood gas analyser was used for all measurements with regular calibration performed to ensure consistency in sample analysis. As a result, high analytical performance in the measurement of $\mathrm{pH}, \mathrm{PaCO}_{2},\left[\mathrm{~K}^{+}\right]_{\mathrm{p}}$ and oximetry parameters were obtained. The system uses an automatic mixing system to obtain a homogenous sample for correct results thereby avoiding vigorous manual mixing, which can also lead to a haemolysed blood gas sample. The analyser prewarmed all samples to 
$37{ }^{\circ} \mathrm{C}$ prior to measurement, and the alpha-stat model was applied for all blood gases analyses.

The primary aim of the study was to describe the relationship between $\mathrm{PaCO}_{2}$ and $\left[\mathrm{K}^{+}\right]_{\mathrm{p}}$. To investigate the independent association between acute hypercarbia and hyperkalaemia, we collected the following preoperative patient variables: age (years), gender, body mass index $\left(\mathrm{kg} / \mathrm{m}^{2}\right)$, current smoker status, ASA physical status classification, history of obstructive pulmonary lung disease, presence of other comorbidities, and surgery urgency. Intraoperative variables collected included the type of laparoscopic surgery, duration of surgery and amount of intraoperative fluid administered. We also collected the ARISCAT score, adjusted for the laparoscopic surgery, which predicts the risk of pulmonary complications after surgery [23, 24].

Inferential statistics were performed with IBM SPSS Statistics for Windows, version 23 (IBM Corp., Armonk, NY, USA). Missing value assessments were performed with $\mathrm{R}$ software 3.5.2 ( $\mathrm{R}$ Development Core Team, Vienna, Austria, 2018) using "mice" and "missMDA" packages. Figure 1 was created using MS Word 365 (16.0.13127.20402) and Fig. 2 was created

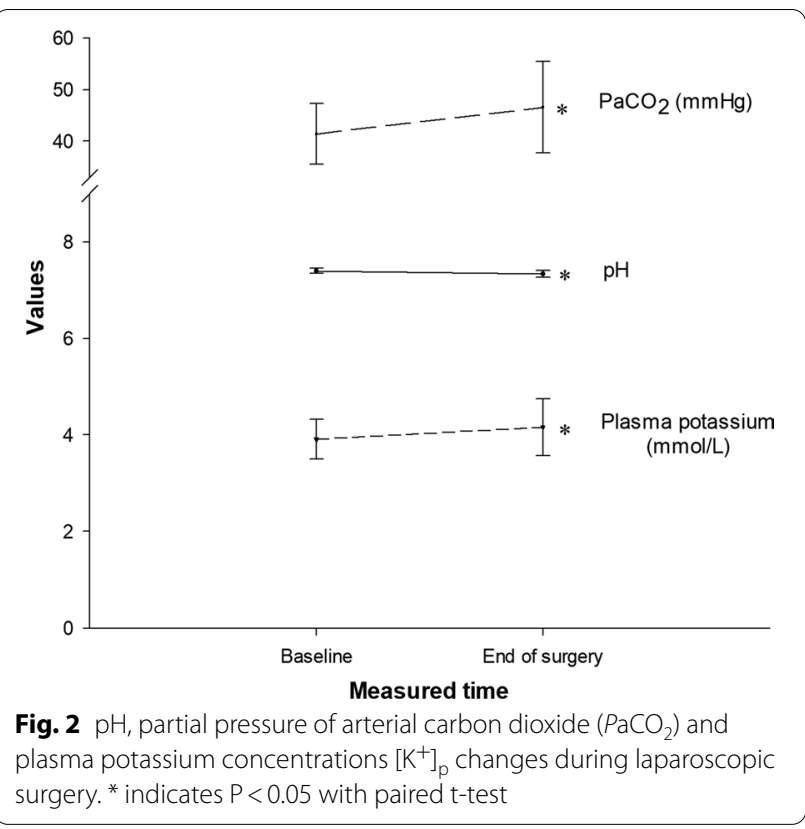

using SigmaPlot for Windows version 12.0 (Systat Software Inc., 2011, U.S.A).

For all continuous variables, data exploration for outliers and missing values was performed. If there were

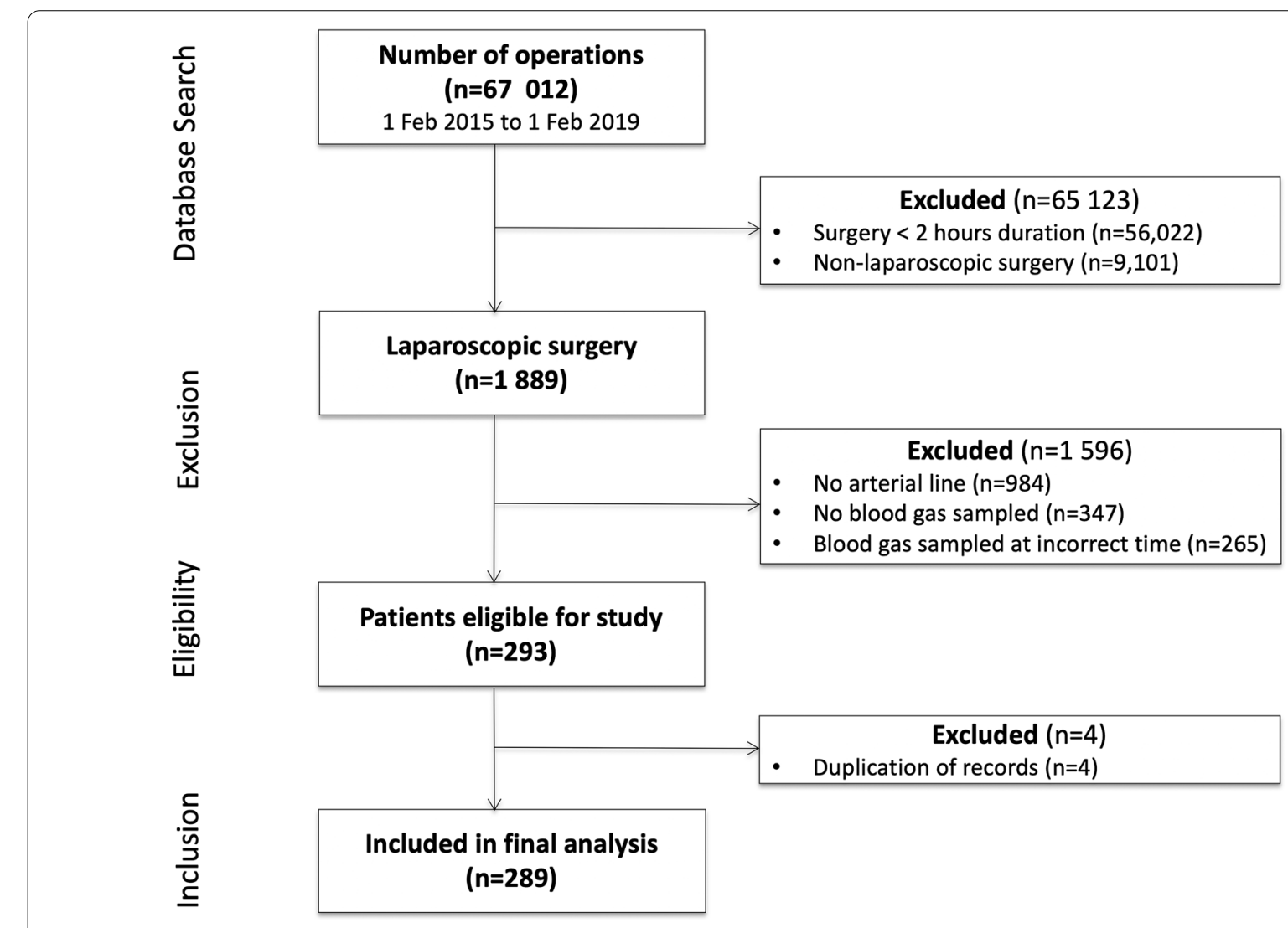

Fig. 1 Study flow diagram 
extreme outliers, winsorization was applied. Only two values from each of baseline $\left[\mathrm{K}^{+}\right]_{\mathrm{p}}$ and $\mathrm{pH}$ at the end of surgery were extreme outliers and were replaced with the most adjacent values. If the missing value rate was below 5\%, we planned a complete case analysis. Normality assumptions were examined with a visual check of the quantile-quantile (Q-Q) plot. Variables of apparent violated normality assumption were treated with non-parametric statistical analysis methods.

Baseline characteristics were presented using descriptive statistics. Values at baseline and at the end of surgery were compared using the paired $\mathrm{t}$-test. To investigate the relationship between the magnitude of $\mathrm{PaCO}_{2}$ changes, $\left[\mathrm{K}^{+}\right]_{\mathrm{p}}$ changes, and patient characteristics, correlation analysis was performed. For the relationship between the magnitude of $\mathrm{PaCO}_{2}$ changes and $\left[\mathrm{K}^{+}\right]_{\mathrm{p}}$ changes, visual checking of the scatter plot and curve-fit analysis using regression were performed with various types of equations. Based on these results, linear regression was performed to clarify the relationship between the magnitude of $\mathrm{PaCO}_{2}$ changes and $\left[\mathrm{K}^{+}\right]_{\mathrm{p}}$ changes, and other patient characteristics.

To establish the final model, the stepwise selection method was used, and assumptions of linear regression were tested with a histogram and a Q-Q plot for multivariate normality, correlation matrix and variance inflation factors for multicollinearity, Durbin-Watson statistics for autocorrelation, and visual checking of the scatter plot for each independent variable for homoscedasticity. Regression diagnostics were performed with the normality test of residuals. Finally, the characteristics of patients who presented with hypercarbia were also evaluated to enhance the understanding of risk factors for intraoperative $\mathrm{CO}_{2}$ retention. All data were presented with mean $\pm S D$, number (percentile), or median (IQR). The statistically inferred values were expressed as mean (95\% confidence intervals $[\mathrm{CI}]$ ) with corresponding effect sizes, and $P$ values. A two-tailed $P$ value of below 0.050 was considered statistically significant.

\section{Results}

A graphical representation of patients undergoing surgery during the study period is presented in Fig. 1. Overall, 1889 patients underwent laparoscopic surgery. Of these, 1596 patients were excluded (no arterial line: $\mathrm{n}=984$, no blood gas analysis performed: $\mathrm{n}=347$, blood gas sampled at incorrect times: $n=265$ ). Two hundred and ninety-three patients fulfilled the study inclusion criteria. Four patients were excluded due to duplication of data from the records. A total of 289 patients were included in the final statistical analysis (Additional file 1: De-identified database).
The mean (SD) age of patients was $63.2 \pm 11.5$ years; $176(60.9 \%)$ patients were male, and the mean (SD) body mass index was $29.3 \pm 6.8 \mathrm{~kg} / \mathrm{m}^{2}$. The mean (SD) corrected ARISCAT score was $29.5 \pm 11.8$, and 51 (17.6\%) patients were current smokers. Patient comorbidities and baseline characteristics are presented in Table 1. Most surgeries were elective, and the median (IQR) duration of surgery was $184 \mathrm{~min}$ (137.3 $\mathrm{min}$ to $240.0 \mathrm{~min})$. For all 6 patients who underwent emergency surgery, the admission diagnosis was acute lower gastrointestinal bleeding. No patient had acute peritonitis and all patients underwent definitive surgery after inpatient optimisation.

Intraoperatively, no patient received intraoperative potassium supplementation except for that contained in Plasma-Lyte 148. The median (IQR) volume of Plasma-Lyte 148 solution administered was $2.0 \mathrm{~L}$ (1.0 L to $2.1 \mathrm{~L}$ ), with an approximate estimated infusion rate of $11 \mathrm{~mL} / \mathrm{min}$. Nine patients (3.8\%) received an intraoperative blood transfusion. The median (interquartile range) number of packed red blood cell units transfused was 1 unit ( 1 unit to 3 units). No patient received a massive blood transfusion. The maximum number of red blood units transfused was three.

Comparisons of $\mathrm{pH}, \mathrm{PaCO}_{2}$ and $\left[\mathrm{K}^{+}\right]_{\mathrm{p}}$ at baseline and at the end of surgery are presented in Table 2. At the completion of the surgery, $\mathrm{PaCO}_{2}$ had increased by $5.18 \mathrm{mmHg}(95 \% \mathrm{CI}, 4.27 \mathrm{mmHg}$ to $6.09 \mathrm{mmHg}$ ) compared to baseline values $(\mathrm{P}<0.001$, Cohen's $d=1.26$,) $\mathrm{pH}$ also decreased reciprocally to the increased $\mathrm{PaCO}_{2}$ $(\mathrm{P}<0.001$, Cohen's $d=0.99)$, with a similarly large effect size observed. $\left[\mathrm{K}^{+}\right]_{\mathrm{p}}$ increased by 0.25 (95\% CI: 0.20 to $0.31) \mathrm{mmol} / \mathrm{L}$ at the end of surgery compared to baseline values $(P<0.001$, Cohen's $d=0.03)$. The effect size of this change was small. Before and after changes in these variables are presented graphically in Fig. 2. Bicarbonate and standard base excess values remained within normal laboratory limits at all time points (Table 2).

Correlation analysis between $\mathrm{PaCO}_{2}$ changes, $\left[\mathrm{K}^{+}\right]_{\mathrm{p}}$ changes and other baseline patient characteristics are presented in Table 3. Increases in $\mathrm{PaCO}_{2}$ correlated weakly with increasing BMI $(\mathrm{r}=0.12, P=0.049)$, and higher $\left[\mathrm{K}^{+}\right]_{\mathrm{p}}$ were associated with type II diabetes mellitus (rho $=0.13, P=0.023$ ). According to curve-fit analysis results, a linear model $\left(R^{2}=0.217, P<0.001\right)$ was suitable because quadratic and squared models resulted in the same proportion of the variance for the $\left[\mathrm{K}^{+}\right]_{\mathrm{p}}$ change associated with $\mathrm{PaCO}_{2}$ changes $\left(\mathrm{R}^{2}=0.217, P<0.001\right.$ for the quadratic and squared models).

Multiple regression analysis evaluating whether $\mathrm{PaCO}_{2}$ changes during surgery significantly predicted immediate changes in $\left[\mathrm{K}^{+}\right]_{\mathrm{p}}$ at completion of surgery demonstrated that a final fitted regression model could predict $33.1 \%$ of the observed variance in $P_{\mathrm{aCO}}\left(\mathrm{R}^{2}=0.331\right.$, 
Table 1 Preoperative and intraoperative variables

\begin{tabular}{|c|c|c|}
\hline Parameters & Patients $(n=289)$ & $\begin{array}{l}\text { Missing } \\
\text { rate (\%) }\end{array}$ \\
\hline Age (years) & $63.2 \pm 11.5$ & 0.00 \\
\hline Male gender & $176(60.9 \%)$ & 0.00 \\
\hline Body mass index $\left(\mathrm{kg} / \mathrm{m}^{2}\right)$ & $29.3 \pm 6.8$ & 0.35 \\
\hline Corrected ARISCAT score & $29.5 \pm 11.8$ & 4.84 \\
\hline Current smoker & $51(17.6 \%)$ & 0.00 \\
\hline \multicolumn{3}{|c|}{ American Society of Anesthesiologists status } \\
\hline Class 1 & $21(7.3 \%)$ & \\
\hline Class 2 & $124(42.9 \%)$ & 2.08 \\
\hline Class 3 & $129(44.6 \%)$ & \\
\hline Class 4 & $9(3.1 \%)$ & \\
\hline No of patients with $\geq 1$ chronic disease & $214(74.0 \%)$ & 0.00 \\
\hline \multicolumn{3}{|l|}{ Types of chronic disease ${ }^{*}$} \\
\hline Obstructive lung disease & $84(29.1 \%)$ & \\
\hline Type II diabetes mellitus & $57(19.7 \%)$ & \\
\hline Essential hypertension & $149(51.6 \%)$ & \\
\hline Renal disease (creatinine $>120$ umol/L) & $25(8.7 \%)$ & 0.00 \\
\hline Hepatic disease (bilirubin > 20 umol/L) & $25(8.7 \%)$ & \\
\hline Coronary artery disease & $46(15.9 \%)$ & \\
\hline Emergency surgery & $6(2.1 \%)$ & 0.00 \\
\hline \multicolumn{3}{|l|}{ Types of laparoscopic procedures } \\
\hline Anterior resection & $61(21.1 \%)$ & \\
\hline Left or right hemicolectomy & $60(20.8 \%)$ & \\
\hline Small bowel resection & $2(0.7 \%)$ & \\
\hline Intestinal bypass & $2(0.7 \%)$ & 0.00 \\
\hline Adrenalectomy & $4(1.4 \%)$ & \\
\hline Colostomy or adhesiolysis & $6(2.1 \%)$ & \\
\hline Cholecystectomy & $10(3.5 \%)$ & \\
\hline Diaphragmatic hernia repair & $1(0.3 \%)$ & \\
\hline Fundoplication & $5(1.7 \%)$ & \\
\hline Sleeve gastrectomy gastric bypass & $17(5.9 \%)$ & \\
\hline Splenectomy & $2(0.7 \%)$ & \\
\hline Pancreatectomy & $1(0.3 \%)$ & \\
\hline Hernia repair & $7(2.4 \%)$ & \\
\hline Liver resection & $20(6.9 \%)$ & \\
\hline Nephrectomy & $45(15.6 \%)$ & \\
\hline Radical prostatectomy & $35(12.1 \%)$ & \\
\hline Pyeloplasty & $1(0.3 \%)$ & \\
\hline Rectopexy & $1(0.3 \%)$ & \\
\hline Removal of pelvic or peritoneal mass & $3(1.0 \%)$ & \\
\hline Exploratory procedures & $6(2.1 \%)$ & \\
\hline Duration of surgical procedure (min) & $184.0(137.3$ to 240.0$)$ & 0.35 \\
\hline Intraoperative fluid administration (I) & $2.0(1.0$ to 2.1$)$ & 1.73 \\
\hline
\end{tabular}

Values are expressed as mean \pm standard deviation or median (interquartile range) for continuous variables, number (percentile) for categorical variables. Missing data rate of each variable is presented.

* Some patients had $>1$ chronic disease
$\mathrm{F}(3,259)=38.915, P<0.001)$. Regression analysis showed that $\mathrm{PaCO}_{2}$ changes, intraoperative Plasma-Lyte 148 administration volume, and a history of type II diabetes mellitus significantly predicted changes in $\left[\mathrm{K}^{+}\right]_{\mathrm{p}}$ at completion of surgery ( $\beta=0.018$ (95\% CI: 0.011 to 0.025 ), $P<0.001 ; \beta=0.061$ (95\% CI: 0.031 to 0.091 ), $\mathrm{P}<0.001$; $\beta=0.154$ ( $95 \%$ CI: 0.023 to 0.284 ), $P=0.021$ respectively). There was no association between $\left[\mathrm{K}^{+}\right]_{\mathrm{p}}$ and duration of surgery $(P=0.102$, Table 4$)$.

Thus, for each $10 \mathrm{mmHg}$ increment of $\mathrm{PaCO}_{2}$ from baseline during surgery, $\left[\mathrm{K}^{+}\right]_{\mathrm{p}}$ increased by $0.18 \mathrm{mmol} / \mathrm{L}$. Furthermore, $\left[\mathrm{K}^{+}\right]_{\mathrm{p}}$ increased by $0.061 \mathrm{mmol} / \mathrm{Lfor}$ each litre of Plasma-Lyte 148 administered, and patients with type II diabetes mellitus experienced a $0.154 \mathrm{mmol} / \mathrm{L}$ greater rise in $\left[\mathrm{K}^{+}\right]_{\mathrm{p}}$ compared to those without.

\section{Discussion}

In a single centre retrospective study describing the association of acute changes in $\mathrm{PaCO}_{2}$ with acute changes in $\left[\mathrm{K}^{+}\right]_{\mathrm{p}}$ in patients undergoing laparoscopic surgery, $\mathrm{CO}_{2}$ pneumoperitoneum induced small but significant increases in $\mathrm{PaCO}_{2}$ and small but significant decreases in $\mathrm{pH}$ during surgery. Moreover, $\left[\mathrm{K}^{+}\right]_{\mathrm{p}}$ increased slightly but significantly at the end of surgery compared to baseline. After adjustment for multiple potential confounders, for every $10 \mathrm{mmHg}$ increment in $\mathrm{PaCO}_{2}$ from baseline, $\left[\mathrm{K}^{+}\right]_{\mathrm{p}}$ increased by almost $0.2 \mathrm{mmol} / \mathrm{L}$. Finally, changes in $\left[\mathrm{K}^{+}\right]_{\mathrm{p}}$ were additionally positively affected by the amount of Plasma-Lyte 148 administered and the presence of type II diabetes mellitus. Given the magnitude of the changes observed, our findings imply that any acute hypercarbic or hyperkalaemic state induced by laparoscopic surgery is probably of limited clinical significance.

Our findings imply that during surgery clinicians should not ascribe large changes in $\left[\mathrm{K}^{+}\right]_{\mathrm{p}}$ to hypercarbia. Other aetiological factors should be considered as a more likely cause of hyperkalaemia. Such differentials should include renal failure, non-renal and endocrine causes, medications and surgical factors. The main hormonal system regulating renal potassium excretion is the reninangiotensin-aldosterone system. Medications used in the perioperative setting that inhibit this system include angiotensin converting enzyme inhibitors, angiotensin II receptor blockers, nonsteroidal anti-inflammatory drugs, and adrenergic beta-antagonists. Other common anaesthesia medications known to cause hyperkalaemia during surgery include suxamethonium, beta-blockers, digoxin, mannitol and some intravenous penicillins (high potassium content). Finally, surgical causes that can result in the release of potassium from injured cells include ischaemia-reperfusion injury, rhabdomyolysis from surgical associated muscle damage, and high-volume blood 
Table 2 Comparisons of $\mathrm{pH}$, partial pressure of arterial carbon dioxide $\left(\mathrm{PaCO}_{2}\right)$ and plasma potassium concentrations $\left[\mathrm{K}^{+}\right]_{\mathrm{p}}$ between baseline and end of surgery

\begin{tabular}{|c|c|c|c|c|c|}
\hline Variable & Baseline & End of surgery & Paired differences & $P$ value & Cohen's $d$ \\
\hline $\mathrm{pH}$ & $7.401 \pm 0.053$ & $7.34 \pm 0.069$ & $-0.061(-0.068$ to -0.054$)$ & $<0.001^{*}$ & 0.99 \\
\hline $\mathrm{PaCO}_{2}(\mathrm{mmHg})$ & $41.44 \pm 5.84$ & $46.61 \pm 8.83$ & 5.18 (4.27 to 6.09$)$ & $<0.001^{*}$ & 1.26 \\
\hline$\left[\mathrm{K}^{+}\right]_{\mathrm{p}}(\mathrm{mmol} / \mathrm{L})$ & $3.911 \pm 0.416$ & $4.162 \pm 0.591$ & 0.251 (0.197 to 0.305$)$ & $<0.001^{*}$ & 0.03 \\
\hline Bicarbonate $(\mathrm{mmol} / \mathrm{L})$ & $24.96 \pm 3.58$ & $23.90 \pm 3.61$ & 1.06 (0.54 to 1.58$)$ & $<0.001^{*}$ & 0.19 \\
\hline Standard base excess (mmol/L) & $0.87 \pm 2.97$ & $-0.93 \pm 2.74$ & $1.80(1.44$ to 2.16$)$ & $<0.001^{*}$ & 0.24 \\
\hline
\end{tabular}

Paired differences were presented with 95\% confidence intervals. The effect size is presented with Cohen's $d$.

* Indicates $\mathrm{P}<0.05$ with paired t-test

Table 3 Correlation analysis between partial pressure of arterial carbon dioxide $\left(\mathrm{PaCO}_{2}\right)$ changes, plasma potassium concentrations $\left[\mathrm{K}^{+}\right]_{\mathrm{p}}$ changes and other parameters

\begin{tabular}{|c|c|c|c|c|}
\hline \multirow[t]{2}{*}{ Variables } & \multicolumn{2}{|c|}{$\mathrm{PaCO}_{2}$ changes } & \multicolumn{2}{|c|}{$\left[\mathrm{K}^{+}\right]_{\mathrm{p}}$ changes } \\
\hline & Coefficient & P value & Coefficient & $P$ value \\
\hline Age & -0.03 & 0.642 & -0.01 & 0.807 \\
\hline ASA classification & -0.06 & 0.315 & 0.04 & 0.546 \\
\hline BMI & $0.12^{*}$ & 0.049 & 0.03 & 0.632 \\
\hline Current smoking status & 0.06 & 0.347 & 0.03 & 0.571 \\
\hline Lung disease & 0.06 & 0.348 & 0.09 & 0.132 \\
\hline Coronary disease & -0.04 & 0.553 & -0.01 & 0.829 \\
\hline Type II diabetes mellitus & -0.04 & 0.534 & $0.13^{*}$ & 0.023 \\
\hline Essential hypertension & -0.05 & 0.394 & 0.02 & 0.679 \\
\hline Renal disease & 0.03 & 0.576 & -0.07 & 0.215 \\
\hline Hepatic disease & -0.03 & 0.568 & 0.09 & 0.128 \\
\hline $\begin{array}{l}\text { Elective / Emergency } \\
\text { operation }\end{array}$ & 0.08 & 0.161 & -0.02 & 0.735 \\
\hline Duration of surgery & 0.02 & 0.783 & 0.10 & 0.102 \\
\hline Corrected ARISCAT score & 0.06 & 0.356 & 0.06 & 0.337 \\
\hline $\begin{array}{l}\text { Intraoperative fluid } \\
\text { amount }\end{array}$ & 0.01 & 0.928 & 0.10 & 0.113 \\
\hline
\end{tabular}

Coefficients are presented as Pearson correlation for continuous variables or Spearman's rho for categorical variables

* Indicates $\mathrm{P}<0.05$

transfusion. In many patients, during surgery the cause of hyperkalaemia is multifactorial.

Our findings concur with the landmark study by Finsterer et al. [8], who prospectively investigated the effects of hypercarbia on $\left[\mathrm{K}^{+}\right]_{\mathrm{p}}$ in 17 patients undergoing major abdominal surgery. The authors induced a model of hypercarbia (mean $\mathrm{PaCO}_{2}$ of $71 \mathrm{mmHg}$ ) by removing the soda-lime absorbers from the anaesthesia circuit, and without changing minute volume ventilation and adding $\mathrm{CO}_{2}$ to the inspiratory gas to obtain elevated end-tidal $\mathrm{CO}_{2}$ concentrations. $\mathrm{PaCO}_{2}$ rose by about $30 \mathrm{mmHg}$ resulting in a decrease in $\mathrm{pH}$ of 0.2-0.25. A linear relationship between $\mathrm{PaCO}_{2}$ and
$\left[\mathrm{K}^{+}\right]_{\mathrm{p}}$ was observed and the authors reported that $\left[\mathrm{K}^{+}\right]_{\mathrm{p}}$ increased by $0.30 \mathrm{mmol} / \mathrm{L}$ after $90 \mathrm{~min}$ of induced hypercarbia. Our findings are also aligned with others [25] showing that $\mathrm{PaCO}_{2}$ and $\left[\mathrm{K}^{+}\right]_{\mathrm{p}}$ are related, even with minor degrees of hypercarbia. Hassan et al. [25], reported that $\left[\mathrm{K}^{+}\right]_{\mathrm{p}}$ increased by $0.39 \mathrm{mmol} / \mathrm{L}$ per every $7.5 \mathrm{mmHg}$ increase in $\mathrm{PaCO}_{2}$, a greater increase compared to the present study. Hassan's findings were almost identical to that reported by Edwards et al. [26], who showed that $\left[\mathrm{K}^{+}\right]_{\mathrm{p}}$ increased by $0.4 \mathrm{mmol} / \mathrm{Lper}$ $10 \mathrm{mmHg}$ change in $\mathrm{PaCO}_{2}$, a doubling of what was observed in the present study.

Our findings however are at variance with the case series of 24 patients undergoing cardiac surgery who were exposed to a $15 \mathrm{~min}$ period of apnoeic or low tidal volume ventilation [9]. Over this time period, $\mathrm{PaCO}_{2}$ increased from $43.6 \mathrm{mmHg}$ at baseline to $83.9 \mathrm{mmHg}$ with $\left[\mathrm{K}^{+}\right]_{\mathrm{p}}$ increasing marginally from $4.16 \mathrm{mmol} / \mathrm{L}$ at baseline to $4.28 \mathrm{mmol} / \mathrm{L}$ at $15 \mathrm{~min}$. This study was limited by a small sample size and exposure to significant hypercarbia for only a 15 min duration. Similarly, Natalani et al. [10] compared the acute changes in $\left[\mathrm{K}^{+}\right]_{\mathrm{p}}$ in acutely hypercapnic patients undergoing rigid bronchoscopy. The sampling time to evaluate the effects of $\mathrm{PaCO}_{2}$ on hyperkalaemia was also of short duration $(20 \mathrm{~min})$, and acute respiratory acidosis did not affect $\left[\mathrm{K}^{+}\right]_{\mathrm{p}}$. These findings suggest that there appears to be both a quantitative and temporal relationship between changes in $\left[\mathrm{K}^{+}\right]_{\mathrm{p}}$ and hypercarbia under anaesthesia, and that acute hypercarbia of short duration may have less of an effect on $\left[\mathrm{K}^{+}\right]_{\mathrm{p}}$ compared to prolonged exposure. As there was no significant association between $\left[\mathrm{K}^{+}\right]_{\mathrm{p}}$ and duration of surgery in this study, and only patients who had a surgical duration of two hours were included, it is likely that the temporal onset of $\left[\mathrm{K}^{+}\right]_{\mathrm{p}}$ change due to a change in $\mathrm{PaCO}_{2}$ is less than two hours.

Our study has several strengths. Data on a relatively large sample size was provided and a detailed description of the acute effects of hypercarbia and its associations with $\left[\mathrm{K}^{+}\right]_{\mathrm{p}}$ during laparoscopic surgery were 
Table 4 Coefficients estimated using linear regression for predicting plasma potassium concentrations $\left[\mathrm{K}^{+}\right]_{\mathrm{p}}$ changes

\begin{tabular}{|c|c|c|}
\hline Variables & Coefficient & $P$ value \\
\hline \multicolumn{3}{|l|}{ Included in the final regression model } \\
\hline $\mathrm{PaCO}_{2}$ changes & $0.018(0.011-0.025)$ & $<0.001$ \\
\hline Intraoperative Plasma-Lyte 148 administration volume & $0.061(0.031-0.091)$ & $<0.001$ \\
\hline Type II diabetes mellitus & $0.154(0.023-0.284)$ & 0.021 \\
\hline \multicolumn{3}{|l|}{ Excluded in the final regression model } \\
\hline Age & 0.084 & 0.464 \\
\hline American Society of Anesthesiologists status & 0.029 & 0.683 \\
\hline Body mass index & 0.046 & 0.703 \\
\hline Smoking history & -0.008 & 0.889 \\
\hline Obstructive lung disease & 0.058 & 0.348 \\
\hline Coronary artery disease & -0.041 & 0.464 \\
\hline Hypertension & 0.014 & 0.847 \\
\hline Renal disease (creatinine > 120 umol/L) & -0.102 & 0.058 \\
\hline Hepatic disease (bilirubin > 50 umol/L) & 0.07 & 0.199 \\
\hline Emergency surgery & -0.036 & 0.497 \\
\hline Duration of surgical procedure & 0.156 & 0.235 \\
\hline Corrected ARISCAT score & 0.082 & 0.475 \\
\hline
\end{tabular}

Coefficient values are expressed with $95 \%$ confidential intervals when corresponding variable is included in the final regression model

analysed. $\quad \mathrm{PaCO}_{2},\left[\mathrm{~K}^{+}\right]_{\mathrm{p}}$, bicarbonate and standard base excess values were collected directly from arterial blood samples and were not amenable to ascertainment bias or derivation. The timing of blood gases in relation to the start and completion of surgery was manually cross-checked with the patients' medical records by two independent investigators, allowing for accurate confirmation of these data points at the start and at completion of surgery. The large dataset examines the impact of laparoscopic surgery on $\mathrm{PaCO}_{2}$ and $\left[\mathrm{K}^{+}\right]_{\mathrm{p}}$ by directly measuring $\mathrm{PaCO}_{2}$ and $\left[\mathrm{K}^{+}\right]_{\mathrm{p}}$ at baseline and at the completion of surgery, allowing a greater understanding of the temporal relationship of changes in $\left[\mathrm{K}^{+}\right]_{\mathrm{p}}$ and $\mathrm{PaCO}_{2}$ to be observed.

Our study has several limitations. It was a single centre study, limiting the external validity of our findings. However, given laparoscopic surgery with $\mathrm{CO}_{2}$ insufflation is utilised worldwide, our findings are likely relevant and externally generalisable. We cannot extrapolate our results to shorter surgical times, to paediatric patients or to patients at high risk of developing hyperkalaemia (renal failure patients, rhabdomyolysis, tumour lysis syndrome etc.). However, the biological principles and physiochemical changes described are likely to apply to all hypercarbic patients undergoing general anaesthesia. As only two blood gases were sampled, the exact onset and rate of change of the findings observed cannot be evaluated. This study was not designed to determine whether there was an association between changes in $\mathrm{PaCO}_{2}$ or $\left[\mathrm{K}^{+}\right]_{\mathrm{p}}$ and the occurrence of detrimental clinical outcomes. Similarly, we did not evaluate the association between changes in $\mathrm{PaCO}_{2}$ or $\left[\mathrm{K}^{+}\right]_{\mathrm{p}}$ with specific medications that are known to be associated with hyperkalaemia such as preoperative use of certain antihypertensive medications e.g. angiotensin-converting enzyme inhibitors, angiotensin II receptor blockers, and/or potassium-sparing diuretics. This data was unable to be collected and we acknowledge this as a limitation of the study. However, this study was designed to evaluate the change in $\mathrm{PaCO}_{2}$ from baseline rather than the absolute value of $\left[\mathrm{K}^{+}\right]_{\mathrm{p}}$ at baseline, which is more likely to be effected by these medications. As the anaesthesia records in our institution are hand-written, and not part of the hospital's electronic medical record system, corresponding end-tidal $\mathrm{CO}_{2}$ values were not able to be collected retrospectively. However, the focus of this study was primarily on the association of $\mathrm{PaCO}_{2}$ and $\left[\mathrm{K}^{+}\right]_{\mathrm{p}}$, rather than end-tidal $\mathrm{CO}_{2}$ and acid-base responses to an increased $\mathrm{PaCO}_{2}$. For all cases the initial $\mathrm{CO}_{2}$ insufflation occurred at a rate of 1 to $5 \mathrm{~L} / \mathrm{min}$ to achieve an intraabdominal pressure of 12 to $15 \mathrm{mmHg}$. We used a constant $\mathrm{CO}_{2}$ flow of approximately 200 to $400 \mathrm{~mL} / \mathrm{min}$ to maintain pneumoperitoneum perioperatively. Given this standard practice for all patients, we cannot make any inferences about the relationship of intraabdominal pressure and changes in $\mathrm{PaCO}_{2}$. Finally, due to the heterogeneity of clinical precipitants for potassium disorders, and the observational nature of this study, our findings are merely associations and do not infer causation. 


\section{Conclusion}

During laparscopic surgery, for every $10 \mathrm{mmHg}$ increase in $\mathrm{PaCO}_{2}$ from baseline, $\left[\mathrm{K}^{+}\right]_{\mathrm{p}}$ increased by almost $0.2 \mathrm{mmol} / \mathrm{L}$. $\left[\mathrm{K}^{+}\right]_{\mathrm{p}}$ was further elevated with the administration of the crystalloid solution Plasma-Lyte 148 and the presence of type II diabetes mellitus. Clinicians should not ascribe larger changes in $\left[\mathrm{K}^{+}\right]_{\mathrm{p}}$ to hypercarbia in this setting and should consider other aetiological factors in their differential diagnosis.

\section{Supplementary Information}

The online version contains supplementary material available at https://doi. org/10.1186/s12893-020-01034-w.

Additional file 1: Table S1. Database_Final_CO2_Study_OctR4_2020.

\section{Abbreviations}

$\mathrm{PaCO}_{2}$ : Partial pressure of arterial carbon dioxide; $\mathrm{CO}_{2}$ : Carbon dioxide; $\mathrm{Cl}$ : Confidence interval; $\left[\mathrm{K}^{+}\right]_{\mathrm{p}}$ : Plasma potassium concentrations; Q-Q: Quantile-quantile.

\section{Acknowledgements}

None.

\section{Authors' contributions}

CRediT (Contributor Roles Taxonomy). LW, DK, RB: Conceptualization, Methodology, Writing- Reviewing and Editing. DKL, DI,: Formal analysis, WritingReviewing and Editing. CG, AH, LF, DB, ST, DJ: Data curation, Writing- Original draft preparation. All authors read and approved the final manuscript.

\section{Funding}

This research did not receive any specific grant from funding agencies in the public, commercial, or not-for-profit sectors.

\section{Availability of data and materials}

The deidentified datasets analysed during the current study are available from the corresponding author on reasonable request.

\section{Ethics approval and consent to participate}

The study was approved by the Austin Health Human Research Ethics Committee (LNR/19/Austin/41) and no additional administrative permissions were required to access the raw data. Given the retrospective design, a waiver of participant consent was granted by the ethics committee.

\section{Consent for publication}

Not applicable.

\section{Competing interests}

The authors declare that they have no competing interests.

\begin{abstract}
Author details
1 Department of Anaesthesia, Austin Health, 145 Studley Road, Heidelberg 3084, Australia. ${ }^{2}$ Department of Surgery, The University of Melbourne, Austin Health, Heidelberg 3084, Australia. ${ }^{3}$ Department of Anesthesiology and Pain Medicine, Korea University Guro Hospital, Guro-Gu, Seoul 08308, Republic of Korea. ${ }^{4}$ Department of Intensive Care, Austin Health, 145 Studley Road, Heidelberg 3084, Australia. ${ }^{5}$ School of Public Health and Preventive Medicine, Monash University, 553 St Kilda Road, Melbourne 3004, Australia.
\end{abstract}

Received: 20 June 2020 Accepted: 27 December 2020

Published online: 07 January 2021

\section{References}

1. Wolf JS. Pathophysiologic effects of prolonged laparoscopic operation. Semin Surg Oncol. 1996;12(2):86-95.
2. Wolf JS, MonkTG, McDougall EM, McClennan BL, Clayman RV. The extraperitoneal approach and subcutaneous emphysema are associated with greater absorption of carbon dioxide during laparoscopic renal surgery. J Urol. 1995;154(3):959-63.

3. Adrogué HJ, Madias NE. Changes in plasma potassium in acute acid-base disturbances. Am J Med. 1981;71(3):456-67.

4. Hishida A, Suzuki H, Ohishi K, Honda N. Roles of hormones in plasma potassium alteration in acute respiratory acidosis in dogs. Miner ElectroIyte Metab. 1992;18(1):56-60.

5. Nuttall FQ. Serum electrolytes and their relation to acid-base balance. Arch Intern Med. 1965;116(5):670-80.

6. Scribner $\mathrm{BH}$, Burnell JM. Interpretation of the serum potassium concentration. Metabolism. 1956;5(4):468-79.

7. van Ypersele SC. Potassium homeostasis in renal failure. Kidney Int 1977;11(6):491-504

8. Finsterer $U$, Luhr G, Wirth AE. Effects of acute hypercapnia and hypocapnia on plasma and red cell potassium, blood lactate and base excess in man during anesthesia. Acta Anaesthesiol Scand. 1978;22(4):353-66.

9. Weinberg L, Russell A, Mackley L, Dunnachie C, Meyerov J, Tan C, Li M, Hu R, Karalapillai D. Relationship between acute hypercarbia and hyperkalaemia during surgery. World J Clin Cases. 2019;7(22):3711-7.

10. Natalini G, Seramondi V, Fassini P, Foccoli P, Toninelli C, Cavaliere S, Candiani $A$. Acute respiratory acidosis does not increase plasma potassium in normokalaemic anaesthetized patients. A controlled randomized trial. Eur J Anaesthesiol. 2001;18(6):394-400.

11. Spurr GB, Liu CT. Intra- and extracellular $\mathrm{K}+$ concentrations of cardiac and skeletal muscle during acute respiratory acid-base alterations. Am J Med Sci. 1966;252(4):413-8.

12. Kilburn $\mathrm{KH}$. Movements of potassium during acute respiratory acidosis and recovery. J Appl Physiol. 1965;21(2):679-84.

13. Clancy RL, Brown EB. Changes in bone potassium in response to hypercapnia. Am J Physiol. 1963;204:757-60.

14. Brown EB, Goott B. Intracellular hydrogen ion changes and potassium movement. Am J Physiol. 1963;204:765-70.

15. Lade RI, Brown EB. Movement of potassium between muscle and blood in response to respiratory acidosis. Am J Physiol. 1963:204:761-4.

16. Mackay JL. Effects of a narcotic level of carbon dioxide on the plasma potassium and respiration of cats. Am J Physiol. 1947;151(2):469-78.

17. Schaefer KE, King CT, Mego JL, Williams EE. Effect of a narcotic level of $\mathrm{CO}_{2}$ on adrenal cortical activity and carbohydrate metabolism. Am J Physiol. 1955;183(1):53-62.

18. Poole-Wilson PA, Cameron IR. Intracellular $\mathrm{pH}$ and $\mathrm{K}^{+}$of cardiac and skeletal muscle in acidosis and alkalosis. Am J Physiol. 1975;229(5):1305-10.

19. Spurr GB, Lambert H. Cardiac and skeletal muscle electrolytes in acute respiratory alkalemia and acidemia. J Appl Physiol. 1960;15:459-64.

20. Critchley LA, Ho AM. Surgical emphysema as a cause of severe hypercapnia during laparoscopic surgery. Anaesth Intensive Care. 2010;38(6):1094-100.

21. Wolf JS Jr, Clayman RV, MonkTG, McClennan BL, McDougall EM. Carbon dioxide absorption during laparoscopic pelvic operation. J Am Coll Surg. 1995:180(5):555-60.

22. Worrell JB, Cleary DT. Massive subcutaneous emphysema and hypercarbia: complications of carbon dioxide absorption during extraperitoneal and intraperitoneal laparoscopic surgery-case studies. AANA J. 2002;70(6):456-61.

23. Canet J, Gallart L, Gomar C, Paluzie G, Vallès J, Castillo J, Sabaté S, Mazo V, Briones Z, Sanchis J, ARISCAT Group. Prediction of postoperative pulmonary complications in a population-based surgical cohort. Anesthesiology 2010;113(6):1338-50.

24. Mazo V, Sabaté S, Canet J, Gallart L, de Abreu MG, Belda J, Langeron O, Hoeft A, Pelosi P. Prospective external validation of a predictive score for postoperative pulmonary complications. Anesthesiology. 2014;121(2):219-31.

25. Hassan H, Gjessing J, Tomlin PJ. Hypercapnia and hyperkalaemia. Anaesthesia. 1979;34(9):897-889.

26. Edwards R, Winnie AP, Ramamurthy S. Acute hypocapneic hypokalemia: an iatrogenic anesthetic complication. Anesth Analgesia. 1977:56(6):786-92.

\section{Publisher's Note}

Springer Nature remains neutral with regard to jurisdictional claims in published maps and institutional affiliations. 